\title{
PROVOCAR O ESTRANHAMENTO NÃO OBSTANTE O RISCO DE SOÇOBRAR: OPÇÃO PARA O ENSINO DE FILOSOFIA NA LICENCIATURA DE EDUCAÇÃO FÍSICA
}

\author{
Provoke the unfamiliarity nevertheless the sinking risk: option \\ for Filosofia's teaching in the Course of Physical Education
}

\author{
Carmen Lúcia Fornari Diez ${ }^{1}$ \\ Ricardo Marinelli Martins ${ }^{2}$
}

\section{Resumo}

Este trabalho é o relato da prática pedagógica na disciplina Filosofia na Educação Física no Departamento de Educação Física da Universidade Federal do Paraná, cujo propósito curricular é discutir as concepções de corpo, a partir do pensamento filosófico, para a compreensão do interesse pelas práticas corporais. Argumenta-se, inicialmente, em prol da presença da filosofia na formação do professor, com ênfase para os de educação física, sob o embasamento dos pensamentos de SAVIANI (1993), DELEUZE (1992), OLIVEIRA (2001), FONTANELIA (1997) e NIETZSCHE ([s.d.]). Em seguida são delineadas as características institucionais e curriculares do curso, as expectativas que acadêmicos têm em relação à formação profissional, o planejamento da disciplina específica de filosofia, bem como as experiências anteriores, que definiram para a vivência aqui relatada, de um naufrágio anunciado. Finalmente, descreveu-se a trajetória percorrida em analogia a uma embarcação em risco de soçobrar, mas lutando por manter-se flutuando e em o seu rumo de reflexão sobre o corpo à luz de pensadores diversos, lançando mão de instrumentos didáticos tais como imagens de arte, poesias, fotos, sons, jogos e outros recursos.

Palavras-chave: Filosofia; Educação Física; Práticas corporais; Pensamento filosófico.

\section{Abstract}

This work is the pedagogical practice reportin discipline "Philosophy in the Physical Education in the Physical Education" in the same Department of "Universidade Federal do Paraná", whose curricularpurpose is to argue the body conceptions, from the philosophical thought, for the interest comprehension by the corporeal practices. It argues, initially, in advantage of the philosophy presence in the teacher's formation, with emphasis for the ones of physical education, under the thoughts basement of SAVIANI (1993), DELEUZE (1992), OLIVEIRA (2001), FONTANELIA (1997) and NIETZSCHE ([s.d.]). Are soon after delineated the course institutional and curricular characteristics, the academic expectations have regarding the professional formation, the philosophy specific discipline planning, as well as the previous experiences, that defined for here related existence, of a announced shipwreck. Finally, it described the trajectory runninged through in analogy to a vessel in sinking risk, but fighting to keep floating and in your reflection direction on the body to the thinkers' several light, using didactic instruments hand suches art images, poetries, photos, sounds, games and other resources.

Keywords: Philosophy - Physical Education; Body conceptions; Philosophical thought.

1 Doutora em Filosofia e História da Educação, professora adjunta do Departamento de Educação Física, Universidade Federal do Paraná.

2 Mestrando em Educação, Departamento de Educação, Universidade Federal do Paraná e ex-monitor da disciplina de Introdução à Filosofia. 


\section{Diário de bordo de um naufrágio anunciado}

Este trabalho é o relato da prática pedagógica na disciplina Filosofia na Educação Física e foi elaborado por monitores e professora titular aqui referidos sob a metáfora 'tripulação' - , quando da realização de uma reflexão sobre a experiência do ano letivo de 2002, a partir dos registros sobre a trajetória percorrida.

Desde o início do ano letivo a tripulação' estava consciente da turbulência dos mares. Em viagens anteriores as embarcações haviam soçobrado, mesmo em outras viagens haviam resultado em percursos mais próximos e por águas tranqüilas. Com tais antecedentes, naturalmente o naufrágio foi anunciado.

\section{O porto de destino}

\section{Componentes teóricos da Filosofia na Educação Física}

A ementa da disciplina prevê a discussão das concepções de corpo a partir do pensamento filosófico, buscando a compreensão do interesse pelas práticas corporais. Os objetivos propostos são: contextualizar a Filosofia, enquanto campo de conhecimento, em suas relações com a Educação Física, e como fundamento epistemológico necessário à formação do educador; interpretar os textos filosóficos em seus liames com o processo de constituição da cultura ocidental; analisar a perspectiva antropológica da educação e da Educação Física; refletir sobre as práticas pedagógicas da Educação Física e suas interconexões com as correntes filosóficas. Aí se desejava aportar.

\section{Argumentos em prol da presença da filosofia na formação do professor de educação física}

A composição curricular dos cursos de formação de professores sempre é temática obrigatória na discussão das instituições educacionais da atualidade. Escolher quais serão as diretrizes da formação, os conteúdos que serão privilegiados e a distribuição deles na grade curricular, qua- se sempre geram grandes discussões. Este panorama não é diferente quando se fala da formação do professor de educação física.

Neste sentido faz-se necessário resgatar a importância da presença da filosofia na formação do educador, e, mais especificamente, na formação do professor de educação física.

Ao tratar da importância acima citada, Saviani (1993, p.37) afirma que a filosofia tem seu ponto de partida na problematização da realidade do educando e exerce papel fundamental na formação do educador a partir do momento em que ao filosofar, ambos podem refletir sobre todas as questões relacionadas ao ambiente educacional. Para ele somente com estas características pode-se confirmar o quão fundamental é a filosofia da educação. Ao perder de vista os problemas que a realidade educacional apresenta como ponto de partida para as reflexões, a filosofia perde também seu sentido de existir na formação do professor.

Partindo de outros prismas de observação, Deleuze (1992), tratando da questão do conhecimento - estabeleceu a relação entre filosofia, ciência e arte, como instâncias que o produzem, diferenciadamente. Afirma que a filosofia não é reserva de domínio dos professores de filosofia, mas uma área para os que se interessam por criações relativas aos conceitos.

Filosofia, ciência e arte são planos irredutíveis, mas podem ser explorados segundo uma mesma estratégia; às instâncias da instauração filosófica, corresponderão instâncias simétricas da instauração artística e científica; plano de imanência da filosofia, plano de composição da arte, plano de referência ou de coordenação da ciência; forma do conceito, força da sensação e figuras estéticas, funções e observadores parciais (p. 277).

Assim, novamente traça-se um paralelo relacional entre a filosofia e o professor, já que o trato do conhecimento - seja ele científico ou artístico - deve estar presente na postura de um educador.

Pensando nisso, corrobora-se aqui com o pensamento de que a educação atual conforma-se no pensamento reducionista e fragmentário de Descartes, revelando em muitos momentos a falta de instantes de reflexão filosófica de professores em sua atividade profissional. Nesta perspectiva, Oliveira (2001, p.3) assevera: 
Ao se considerar as relações entre a filosofia de Descartes, o corpo e a educação, surgiram as seguintes perspectivas de análise. Por um lado, a constituição de um modelo escolar que busca conformar uma corporeidade "adequada" para alunos e alunas, legitimando tempos e espaços para o "corpo" e para a "mente". Por outro lado, a constituição de teorias de aprendizagem que "desencarnam" o sujeito que aprende. Verifica-se a presença de uma forma particular de racionalidade que instaurou como legítimas formas particulares e restritas de produção de conhecimento.

É, inclusive, importante que se traga esta discussão com mais clareza para o ambiente do professor de educação física, já que o objeto de estudo e trabalho dele - mesmo que se trate de uma área do conhecimento que ainda discute constantemente suas bases epistemológicas - é o corpo e o movimento humano.

Neste sentido, mesmo que timidamente, coloca-se aqui em discussão o conceito de corpo que se faz presente nos ambientes educativos. Um corpo tratado unicamente como um complexo conjunto de máquinas, que merece atenção isolada para cada uma de suas partes. Esta forma de pensamento senão constrói pelo menos consolida uma forma de processo educacional. Aponta-se então a filosofia como possibilidade para que este entendimento possa ser repensado.

Segundo Nietzsche ([s.d.]) a disjunção do homem grego resultou do combate entre existência estética e a racionalidade e pode ser pensada como reprodução da metáfora da disputa entre Sócrates e Homero pela mente de Atenas. Para este filósofo, a fissura abalou a unidade deste homem prejudicando sua leitura e vivência do mundo.

Fontanella (1997) interpreta que este ser, incitado à discordância visceral com ele próprio, tem na arte e na conjunção desta com a corporeidade as alternativas de reconciliar-se, de restaurar-se em sua inteireza. Ou seja, é da estética que se pode iniciar um projeto de re-humanização. Nesta linha de pensamento, aponta que existem alguns momentos em que o homem pode se recuperar. Dentre estes momentos pode-se destacar - já que este texto trata da filosofia na formação do professor de educação física - a dança, já que "o corpo não dança, a razão não dança. $\mathrm{O}$ homem dança. Há um embalo tão humano e ra- cional quanto natural, quando o homem dança. Natureza, entorno, som, convívio, alegria, ritmo, enlevo, existência, convivência." (p. 21) e o esporte, interpretando que "o homo ludens também é simplesmente homem. Não como o intelectual. Age todo ele em consonância com o meio, com o universo, sem precaver-se disso. É o homem indiviso." (p.21, grifo do autor).

As duas manifestações citadas pelo autor - dança e esporte - são constantes da educação física em suas mais variadas possibilidades educativas, sendo encontradas desde a disciplina curricular da educação básica até os altos níveis de performance, o que revela que dentro de um processo de busca por um homem que reencontre sua humanidade o professor de educação física tem condições de assumir papel grandioso, sendo para isso necessário que reflita filosoficamente sobre as condições apresentadas por estas manifestações nas constituições educacionais contemporâneas.

\section{O porto de partida}

O curso de licenciatura em Educação Física, apesar de ter por desígnio formal a preparação de professores, está alocado institucionalmente do Setor de Ciências Biológicas e, uma vez que não se oferecia a opção de bacharelado - até 2002 - , congregou muitos estudantes interessados em formação profissional para treinamento esportivo, condicionamento físico, etc. Uma vez que o currículo se pauta nessas expectativas, a maior parte do corpo docente também privilegia a área biológica.

Diante disto, a 'tripulação' estudou o diagrama e planejou a travessia buscando alternativas para amenizar as sensações provocáveis pela maresia da leitura necessária: a professora se responsabilizou por selecionar e elaborar textos, além de ministrar as aulas expositivas; aos monitores coube a criação de dinâmicas, o fomento dos diálogos e reflexões e, para não fugir à tradição, dos registros de freqüências e notas.

Além disso, foram agendadas reuniões semanais entre os tripulantes, de modo a avaliar e redirecionar a nau para rotas possíveis, contando com possíveis mudanças dos ventos. 
Anúncio do naufrágio iminente: dificuldades de inserção de um e lemento quase alienígena

As possibilidades da filosofia para o professor de educação física estão - mesmo que de maneira resumida - postas. Porém faz-se necessário discutir o quanto desta importância tem sido absorvida e respeitada por acadêmicos e professores destes cursos de licenciatura. Muitas são as dificuldades de inserção da filosofia nesta formação. Uma resistência que se apresenta de várias maneiras - desde os futuros professores em formação até a forma como a educação física é vista nas instituições de ensino.

Um destes problemas está diretamente ligado à composição curricular dos cursos de licenciatura em educação física. Por se tratar de uma área de atuação profissional muito ampla - já que o licenciado tem a possibilidade de exercer sua atividade profissional em muitos ambientes além da escola - os cursos, em sua grande maioria, são compostos de uma série de áreas distintas do conhecimento, e, no cotidiano, não conseguem se aproximar. Ou seja, o aluno sai da graduação com inúmeros retalhos de tecidos completamente distintos e uma agulha com linha. Cabe a ele - e unicamente a ele - costurar todos os retalhos para intervir profissionalmente.

Este primeiro problema caracteriza um segundo, que diz respeito ao perfil dos alunos egressos neste curso. Por conta do grande leque de atuação já citado, a grande maioria dos que procuram a licenciatura em educação física não tem a intenção inicial de serem professores, tendo seus interesses direcionadas à academia, ao trabalho como personal trainer ou ao lazer e à recreação. Esta situação induz a uma resistência destes alunos aos conhecimentos que tratam das questões educacionais. As disciplinas que se aproximam diretamente da licenciatura acabam sofrendo discriminação, o que traz dificuldades à inserção da filosofia.

Seguindo esta linha de raciocínio, o curso de que se fala aqui acaba por compor-se em aliado à constituição dos conceitos de corpo hegemônicos, onde a necessidade de esculpir corpos segundo modelos de beleza padronizados segundo valores da classe dominante assume papel de disciplinar o corpo. Verdadeiras indústrias da beleza se espalham por toda parte, na promessa da distribuição do verdadeiro elixir da juventude estas instituições deixam de perceber valores que deveriam estar listados nos quesitos integrantes de uma pessoa bela.

Não há academias especializadas em malhação do espírito e ainda não se inventou a transfusão de conhecimentos e valores de uma pessoa a outra ou do computador à mente, de modo a fazer coincidir a estética da aparência com a beleza da essência. (...) Menos livrarias, mais academias de ginástica. Morreremos todos esbeltos e saudáveis; o cadáver, impávido colosso, sem uma celulite (FREI BETO, 2000, p.29).

E tudo isso está presente na educação física, visto que ela pode consolidar algumas destas relações ou pensar em sua transformação.

E para além das questões internas do curso, outras dificuldades podem ser listadas. As caricaturas instituídas, de um lado, do filósofo - aquele ser de corpo frágil com a mente dissociada de realidade - , e de outro, do professor de educação física como um conjunto de músculos cujos movimentos se processam sem o comando do cérebro, estigmatizaram as duas áreas do conhecimento, da mesma forma que Platão cindiu corpo e alma e que a racionalidade ocidental classificou a cultura humana segundo a bipolaridade utilitarista.

Como reflexo dessa lógica dual, tanto o professor de filosofia encontra dificuldade para motivar seus alunos à leitura e à reflexão, como o de Educação Física se depara com o preconceito de que sua prática pedagógica se reduz a "distrair" seus alunos provocando disputas esportivas ou entretenimentos diversos, divorciados da relação educativa. Esta composição revela o preconceito encontrado por este professor em seu ambiente de trabalho, já que algo que vá além do esperado momento de "descanso da mente" é sempre encarado com olhos muito pouco incentivadores pela comunidade escolar.

Assim - ao apresentar esta grande lista de possibilidades e limitações - o ensino de filosofia para futuros professores de educação física torna-se um desafio, tanto para alunos quanto para professores. 


\section{Tentando manter a embarcação} flutuando

Tendo nas mãos o desafio já exposto, pretendeu-se mostrar aos estudantes a filosofia como facilitadora e não um castigo na vida acadêmica.

Buscando não fugir da especificidade do curso, a disciplina foi pensada a partir dos conceitos de corpo nos mais variados pensamentos filosóficos. Sempre partindo do corpo - através de imagens de arte, fotos, sons e outros recursos - a disciplina se propôs a pensar seu objeto na história da filosofia, sob o prisma da filosofia da educação.

No entanto muitas dificuldades foram encontradas. Em se tratando de uma disciplina que propõe a reflexão, se faz necessária muita leitura e a falta de disposição para a leitura de textos filosóficos por parte dos alunos limitou a reflexão filosófica em muitos aspectos, e esta configuração mereceu atenção redobrada. Mesmo que sem muito êxito, a alternativa inicial foi reconstruir os textos, afim de que seu tamanho diminuísse, facilitando assim a leitura. Os resultados não foram tão bons quanto os esperados, manifestando a necessidade que novos instrumentos fossem pensados.

Assim surgiram diversas possibilidades, sendo que aqui serão relatadas apenas algumas consideradas mais significativas.

Inicialmente, apostando no sentido lúdico da temática dos deuses, solicitou-se pesquisa bibliográfica sobre a mitologia grega. Os resultados foram apresentados de formas diversas, dentre as quais se sobressaiu a dança das narrativas mitológicas. Coreografias diversas explicaram as especificidades das personificações do Olimpo: Hércules fisioculturista, Faunos ginastas, Ninfas dançarinas, Medusas de olhares penetrantes paralisado os cidadãos, etc. Daí a reflexão foi encaminhada aos mitos presentes na educação e na educação física da sociedade globalizada.

Sob o entendimento de que filosofia e concretude da existência convergem, ou seja, que a primeira se propõe à reflexão da segunda, preparou-se uma unidade que se prestou a iniciar uma discussão com respeito às bases biológicas do conhecimento, com um capítulo da disserta- ção de Mestrado em Filosofia, que trata da teoria biológica de Humberto Maturana (GRACIANO, 1997). Na análise do texto buscou-se relacionar seus conteúdos com os das disciplinas biológicas, especialmente de Genética.

Para estudar a visão de que somos "condenados à liberdade" utilizou-se um texto didático com alguns dos pensamentos de Ortega y Gasset. Com base nesse prisma existencialista, foi proposta uma dinâmica de RPG (Role Play Game), na qual os participantes precisavam realizar escolhas difíceis, uma vez que as situações simuladas se referiam a relações afetivas e axiológicas pertinentes à vida, com enfoque nas questões do corpo.

A dinâmica proporcionou material para muita discussão, visto que as escolhas de cada um representam uma história e podem revelar traços que tangem a construção do conhecimento e opções educacionais.

Dando continuidade à disciplina, foi proposto um seminário aos alunos, afim de que se pudesse estudar com mais profundidade um texto clássico de Platão, O Fédon. O texto foi dividido em oito partes e a turma em oito equipes. Cada equipe ficou responsável por uma parte do texto, sendo que no momento da escolha de seu fragmento o grupo também recebeu a ordem de utilizar um recurso audiovisual específico em sua apresentação. Os recursos propostos foram teatro, história em quadrinhos, literatura e/ou música e vídeo.

Dentre uma série de trabalhos muito pouco preocupados com o texto de Platão, pôdese observar também ótimas manifestações artísticas propondo a reflexão filosófica, a exemplo do trabalho de um grupo do primeiro ano que produziu a paráfrase do poema "Vou-me embora pra Pasárgada, de Manoel Bandeira":

\section{VOU-ME EMBORA P'RAS IDÉIAS}

(Paráfrase do poema Vou-me embora pra Pasárgada, de Manoel Bandeira)

Vou-me embora pras idéias

Lá melhor eu estarei

Lá tenho as respostas que eu quero

As demais encontrarei

Vou-me embora pras idéias 
Vou-me embora pras idéias

Aqui eu não sou feliz

Lá as respostas são ventura

Assim, tão completamente

Que vemos que as teorias

Da origem e perecer da gente

Vêm a ser diferentes

De modo que não vinguem

Encontrarei de forma fática

A verdade tão completa

Que não levarei a cabo

Aquilo que não encaixe

No conceito da Idéia

O Belo, o Justo, o Vasto

Em si existem em primo

De modo que a alma aclara

Conceitos pré-concebidos

Relembrando o conhecido

Que dantes já abarcara

Vou-me embora pras idéias

Da idéia resulta tudo

Como a explicação

De que o belo não é belo,

Não há aqui outra razão,

Porque no Belo em si,

Tem aquele uma participação

Não importando o modo

Como essa participação se dá

De qualquer causa que insistes

Em descobrir o conceito

Não deves sentir-te triste

Se a ciência não der jeito

- Lá melhor eu estarei

Terei as respostas que quero

As demais encontrarei,

Vou-me embora pras idéias

No início do segundo semestre letivo com o intuito de memorização dos conteúdos trabalhados - foi organizado um "caça ao tesouro" de revisão das matérias estudadas até aquele momento. Na forma de um jogo de perguntas, respostas e charadas que se encontravam espalhadas por todo o espaço físico do departamento de educação física, os alunos puderam revisitar os conhecimentos já visualizados.

Mesmo não atingindo muita profundidade - no que diz respeito às reflexões filosóficas
- o caça serviu como boa alavanca para os trabalhos do segundo semestre.

Finalmente, na atividade de finalização da disciplina, promoveu-se um banquete filosófico. Cada turma - organizada em seis equipes - responsabilizou-se por pesquisar na bibliografia filosófica variados temas - 0 amor, o belo, prazer $\mathrm{e}$ desejo, sexualidade, etc... - e discuti-los comendo frutas e pães integrais e bebendo vinho, como alegoria revivida do contexto da filosofia clássica.

\section{Continuidade da deriva como estranhamento, como incitação ao pensar}

Partindo das experiências acima citadas pode-se estabelecer uma série de possibilidades de análise.

A dificuldade constante da presença da filosofia nos cursos de licenciatura em educação física é uma realidade que não pode ser ignorada. É preciso que alunos e professores possam repensar seus papéis enquanto profissionais da educação e neste sentido refletir sobre suas atitudes.

Muitas das dificuldades descritas aqui não puderam ser dizimadas no ano de trabalho descrito, porém pode-se afirmar que foram minimizadas. Naturalmente muitos alunos continuaram acreditando que a reflexão filosófica "é uma viagem" e, não raramente, "na maionese". Outros tantos riram muito e privilegiaram a dança pela dança, a degustação de frutas e vinhos em si, a atividade física da caça ao tesouro, a interpretação psicológica das escolhas existenciais...

Quanto à viagem, sob o ponto de vista da "tripulação", o mais importante foi o processo, aquilo que se aprendeu na tentativa de ensinar, que pode ser explicado na paráfrase do Soneto da Separação, de Vinícius de Moraes, também elaborada pelos alunos:

\section{SONETO DA IMORTALIDADE}

Para tudo em minha morte estarei pronto Antes, e com tal zelo, e sempre e tanto Que mesmo em face do maior espanto Dela se fortaleça mais meu pensamento 
Quero entender que após este momento

Felicidade hei de encontrar num tanto

Confiança, sabedoria e encanto

Aprimorando o meu conhecimento

dure

E ainda que mais tarde a alma não per-

Quem sabe perecendo no corpo de quem

vive

Quem sabe a destruição, fim que concla-

mas

Possa não reviver a razão que exprime

Que não seja imortal, como declamas

Mas que seja infinita enquanto dure.

Isto posto, conclui-se que, apesar dos mares bravios e do naufrágio anunciado, a nau da disciplina Filosofia na Educação Física conseguiu, relativa mas bravamente, flutuar e avançar em direção a um porto - não seguro - do estranhamento provocativo, pois deseja-se que seja instigante do questionamento e desestabilizador das certezas. Enfim, a perspectiva é de galgar novos espaços para a filosofia na reflexão sobre o corpo - objeto de pesquisa primordial ao professor de educação física, pois se entende que, tanto os licenciados, como os bacharéis formados nos cursos de educação física são, sobretudo, educadores.
Referências

DELEUZE, Gilles; GUATTARI, Félix. O que é filosofia? Trad. Bento Prado Jr. E Alberto Alonso Muñoz. Rio de Janeiro: Editora 34, 1992.

FONTANELLA, F. C. 0 corpo no limiar da subjetividade. Piracicaba: Editora UNIMEP, 1997.

FREI BETO. Como deixar-se moldar pelo sistema. Revista Caros Amigos, São Paulo, v.4, n.42, 2000.

NIETZSCHE, F. W. A filosofia na idade trágica dos gregos. Trad. Maria Inês Madeira de Andrade. Lisboa: Edições 70, [s.d.].

OLIVEIRA, C. M.; SILVA, A. M. Reflexões sobre a filosofia de Descartes: subsídios para compreender as relações entre corpo e educação. IN: CONGRESSO BRASILEIRO DE CIÊNCIAS DO ESPORTE, 12. Caxambú, 2002. Anais do XII Congresso Brasileiro de Ciências do Esporte, Caxambú: [s.n.], 2002.

SAVIANI, D. Educação: do senso comum à consciência filosófica. 11 ed. Campinas: Autores Associados, 1993.

NIETZSCHE, Friedrech Wilhelm. A filosofia na idade trágica dos gregos. Trad. Maria Inês Madeira de Andrade. Lisboa: Edições 70, [s.d.].

GRACIANO, M.M.C. A teoria biológica de Humberto Maturana e sua repercussão filosófica. 1997, f.47-62. Dissertação (Mestrado em filosofia) - UFMG, Belo Horizonte, 1997.

Recebido em 08/10/2003 Aprovado em 10/12/2003 